\title{
Elastic uplift in southeast Greenland due to rapid ice mass loss
}

\author{
Shfaqat A. Khan, ${ }^{1}$ John Wahr, ${ }^{2}$ Leigh A. Stearns, ${ }^{3}$ Gordon S. Hamilton, ${ }^{3}$ Tonie van Dam, ${ }^{4}$ \\ Kristine M. Larson, ${ }^{5}$ and Olivier Francis ${ }^{4}$ \\ Received 25 July 2007; revised 27 September 2007; accepted 5 October 2007; published 1 November 2007.
}

[1] The rapid unloading of ice from the southeastern sector of the Greenland ice sheet between 2001 and 2006 caused an elastic uplift of $\sim 35 \mathrm{~mm}$ at a GPS site in Kulusuk. Most of the uplift results from ice dynamic-induced volume losses on two nearby outlet glaciers. Volume loss from Helheim Glacier, calculated from sequential digital elevation models, contributes about $\sim 16 \mathrm{~mm}$ of the observed uplift, with an additional $\sim 5 \mathrm{~mm}$ from volume loss of Kangerdlugssuaq Glacier. The remaining uplift signal is attributed to significant melt-induced ice volume loss from the ice sheet margin along the southeast coast between $62^{\circ} \mathrm{N}$ and $66^{\circ} \mathrm{N}$. Citation: Khan, S. A., J. Wahr, L. A. Stearns, G. S. Hamilton, T. van Dam, K. M. Larson, and O. Francis (2007), Elastic uplift in southeast Greenland due to rapid ice mass loss, Geophys. Res. Lett., 34, L21701, doi:10.1029/2007GL031468.

\section{Introduction}

[2] The dominant mode of mass loss from the Greenland ice sheet is discharge through fast flowing outlet glaciers. Since 2000, the rates of ice discharge from several glaciers (notably Kangerdlugssuaq (KG) and Helheim glaciers (HG) in East Greenland, and Jakobshavn Isbr (JI) in West Greenland) have more than doubled as a result of significant accelerations in flow speed [Rignot and Kanagaratnam, 2006; Dietrich et al., 2007]. The sudden speed-ups of those glaciers coincided with observed thinning rates of 15-90 $\mathrm{m} \mathrm{yr}^{-1}$ [Joughin et al., 2004; Stearns and Hamilton, 2007; Howat et al., 2005] and indicate a significant mass imbalance in parts of the ice sheet.

[3] Ice volume loss due to coastal thinning of $\sim 90 \mathrm{~m} \mathrm{yr}^{-1}$ would result in a rapid mass unloading of the earth's crust, and cause deformation that should be detectable using GPS observations. Surface displacements due to a load depend on the amplitude of the load and its distance to the observing point. Here we use observed volume losses of $\mathrm{HG}$ and $\mathrm{KG}$, derived from repeat digital elevation models, to estimate their contributions to recent crustal uplift at Kulusuk, East Greenland, detected in a GPS time series. These two glaciers account for about two thirds of the observed uplift. We attribute the remaining uplift signal to

\footnotetext{
${ }^{1}$ Danish National Space Center, Technical University of Denmark, Copenhagen, Denmark.

${ }^{2}$ Department of Physics and Cooperative Institute for Research in Environmental Sciences, University of Colorado, Boulder, Colorado, USA.

${ }^{3}$ Climate Change Institute, University of Maine, Orono, Maine, USA.

${ }^{4}$ Faculty of Sciences, Technology, and Communication, University of Luxembourg, Luxembourg.

${ }^{5}$ Department of Aerospace Engineering Sciences, University of Colorado, Boulder, Colorado, USA.
}

Copyright 2007 by the American Geophysical Union. 0094-8276/07/2007GL031468 mass loss from elsewhere along the Southeast Greenland coast.

\section{GPS Analysis}

2.1. GPS Network and Data Processing

[4] This study focuses on uplift due to mass loss of the major outlet glaciers in southeast Greenland near the GPS site at Kulusuk (KU, the red dot in Figure $1 \mathrm{~b}$ ). The KU uplift is estimated relative to four GPS sites located along the edge of the ice sheet: KE (Kellyville), TH (Thule 2), SC (Scoresbysund) and QA (Qaqortoq). To estimate site coordinates the GIPSY-OASIS II software [Zumberge et al., 1997] developed at the Jet Propulsion Laboratory (JPL) is used. We use GPS orbits, earth orientation, and clock products provided by JPL and based on a global network of GPS sites. All GPS data were processed in the same manner as described by Wahr et al. [2001], except that solutions were aligned with ITRF05 through the standard application of translation, rotation, and scale factors [Altamimi et al., 2007]. Since this study focuses on uplift at $\mathrm{KU}$ relative to other Greenland sites, frame uncertainty and frame drift can be ignored.

\subsection{Vertical Surface Motions at Kulusuk}

[5] Figure 2a shows daily values of KU vertical position relative to $\mathrm{KE}$ (KU-KE). Each dot represents a daily relative solution, and the solid white line shows the sum of the best fitting semi-annually, quasi-annually, inter-annually and secularly varying terms. Annual effects due to surface mass loads caused by the atmosphere, ocean, and water/snow/ice on land, can have a varying amplitude. We therefore fit a quasi-annually varying term with variable amplitude. Due to large data gaps at KU between 1996 and 2000, we only use data from mid-2000 to present.

[6] Figure 2b shows the daily KU-KE residuals, obtained by removing the fitted signal from the filtered daily values of vertical positions. The daily residuals are not entirely random. They arise from a combination of measurement errors and mis-modeled signal, and we use them as an estimate of the total error in the filtered daily data. To do so, we first determine their decorrelation time.

[7] Figure 2c shows the autocorrelation for KU-KE using the daily residuals. The autocorrelation is defined as 1 at $\tau=0$. Note that the autocorrelation reaches the $95 \%$ confidence band (between by the two dashed horizontal lines) when the time lag reaches 25 days, and stays inside that band for $\tau>25$ days. Thus, it has decreased to its $\tau=\infty$ limit at lag times of about 25 days and longer. Hence, a decorrelation time of 25 days is used to construct multi-day averages for KU-KE.

[8] These averages are used to construct error estimates. Let $1 \sigma_{i}$ denote the 1-sigma formal error of the $i$ 'th day, as 


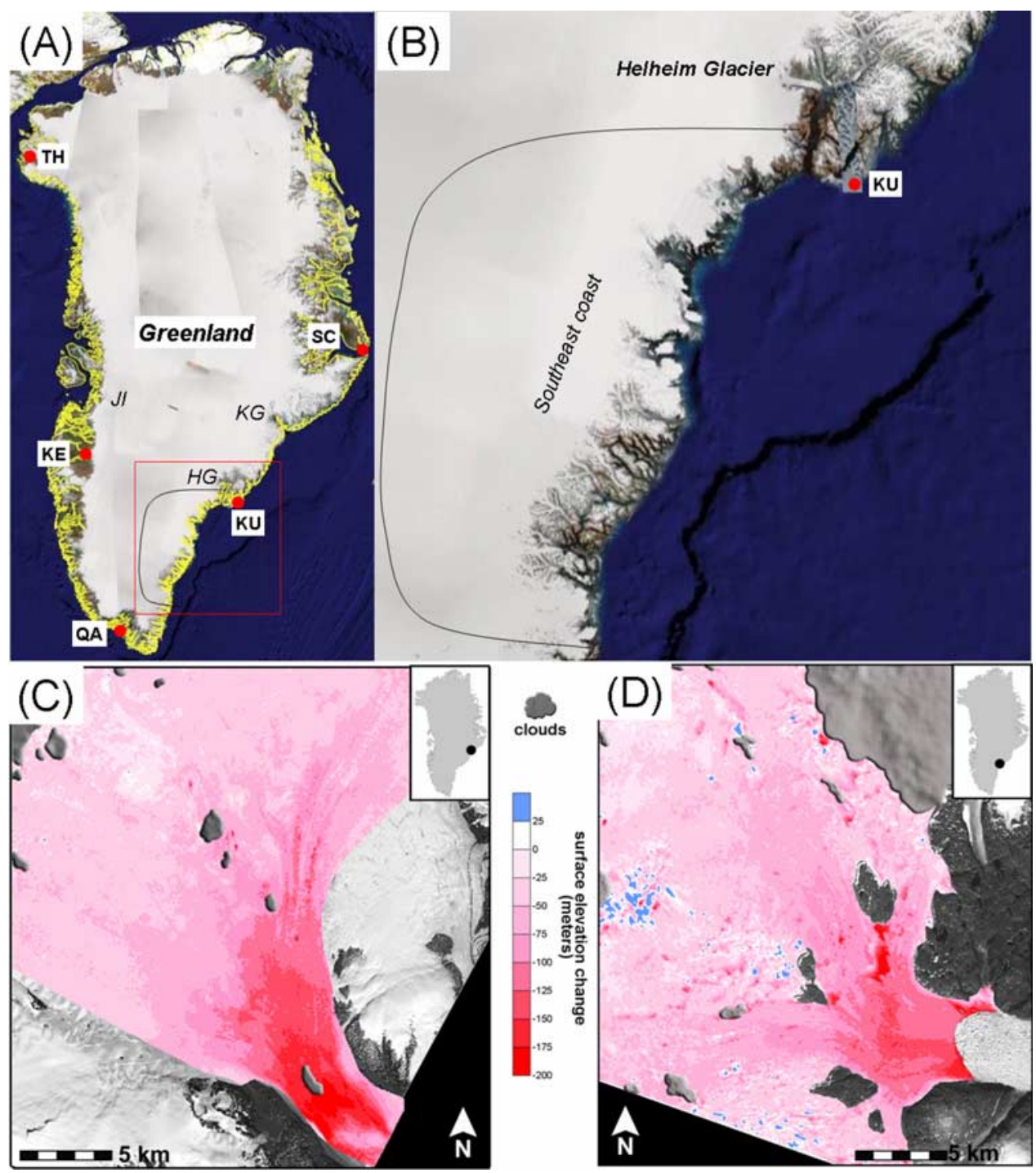

Figure 1. (A) Map of Greenland and location of the GPS sites. (B) Map of southeast Greenland. (C) KG: Maps of surface elevation change over a $1750 \mathrm{~km}^{2}$ area between July 2001-July 2006. (D) HG: Maps of surface elevation change over a $1040 \mathrm{~km}^{2}$ area between June 2002-August 2005.

generated by the GIPSY-OASIS software. This error estimate does not include orbit errors, tropospheric modeling errors, or multipath errors. A more realistic error can be obtained by multiplying the $1 \sigma_{i}$ formal errors by a constant, $c_{m}$, where $m$ denotes the m'th 25-day interval, and $c_{m}$ is only constant within this interval. Using $\chi^{2}$ fitting [Press et al., 1992] an average value is fit to the daily residuals within the m'th interval, after assigning each daily residual an error of $\sigma_{c, i}=1 \sigma_{i} c_{m}$. The constant, $c_{m}$, is obtained by requiring that the final $\chi^{2}$ value equals the number of degrees of freedom (number of observations minus number of unknowns). The $\sigma_{c, m}$ are thus based on the scatter of the daily values about their mean within the m-th interval. However, the mean value of the daily residuals is also an error and therefore added (in quadrature) to $\sigma_{c, m}$, to obtain a final estimate of the uncertainty in the m'th 25 -day value. For each interval we thus estimate a mean value and an error. The errors provide a more realistic error estimate than the $1 \sigma_{i}$ values, in that they include the effects of temporally correlated errors: e.g. orbit errors, tropospheric modeling errors, and multipath errors.

[9] Figure $2 \mathrm{~d}$ shows the multi-day averages at KU and their assigned errors. The semi-annually and quasi-annually varying terms are removed. The solid line shows the interannually varying term. The method of determining uplift at KU relative to $\mathrm{TH}, \mathrm{QA}$ and $\mathrm{SC}$ is similar to that described above.

\subsection{Postglacial Rebound (PGR)}

[10] Our goal is to use the GPS trends to learn about ongoing changes in ice. But these trends must first be corrected for the effects of PGR: the earth's viscoelastic response to past ice variability. PGR predictions computed using the global ICE-5G deglaciation model and VM-2 viscosity profile [Peltier, 2004] suggest present-day uplift rates of $-1.7 \mathrm{~mm} \mathrm{yr}^{-1}$ at $\mathrm{KU}$ and $-3.3 \mathrm{~mm} \mathrm{yr}^{-1}$ at $\mathrm{KE}$; with $-0.1,2.0$, and $1.0 \mathrm{~mm} \mathrm{yr}^{-1}$ at $\mathrm{TH}, \mathrm{SC}$ and QA, respectively. Negative values imply subsidence, and result from the fact that in ICE-5G the mass of the west Greenland ice 

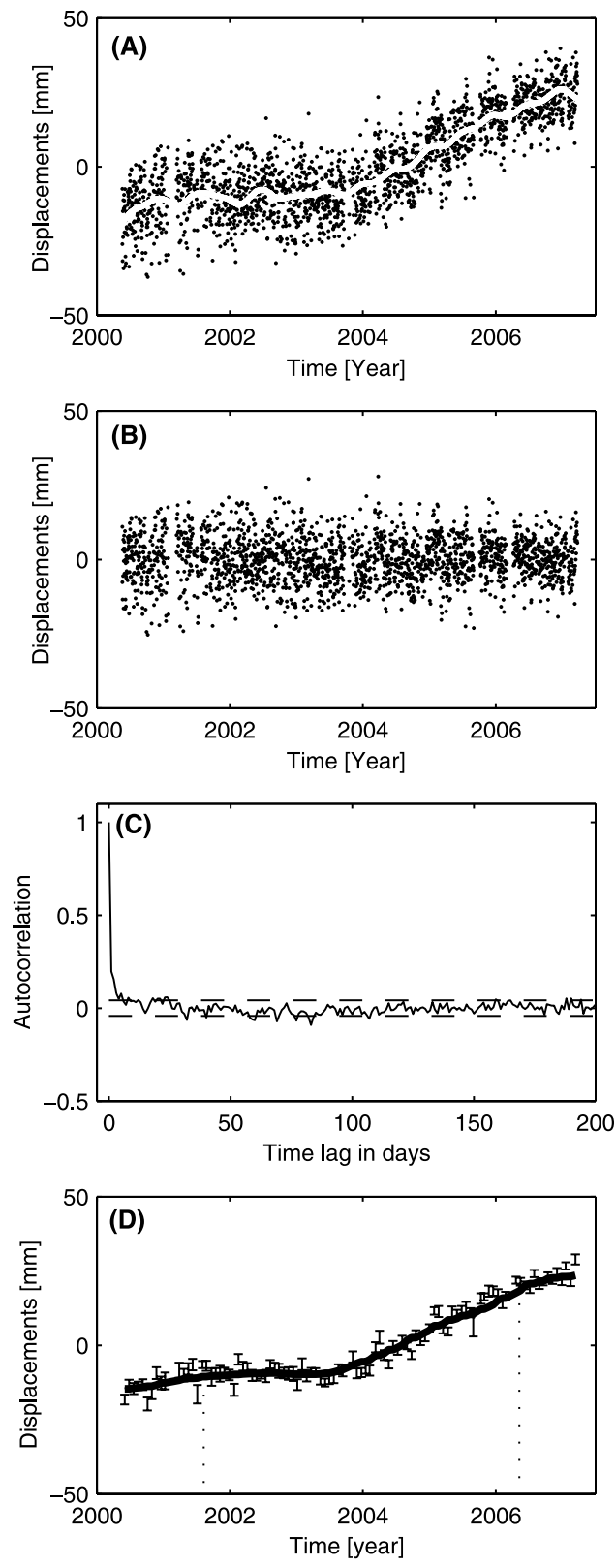

Figure 2. (A) Daily values of vertical positions at KU relative to KE. The solid curve shows the best fitting semiannually, quasi-annually, inter-annually and secularly varying terms. B) The daily residuals (the difference between the daily values and the solid curve in panel A). C) Autocorrelation function for KU-KE. The time lag is given in days and by definition the autocorrelation is set to 1 at time lag $=0$. The dashed horizontal lines denote the $95 \%$ confidence band. D) 25-day averages at KU relative to $\mathrm{KE}$. The solid curve shows the inter-annual signal.

sheet increased subsequent to the mid-Holocene climatic optimum [Tarasov and Peltier, 2002]. The model does not include a corresponding increase in southeast Greenland, which is why the predicted subsidence is largest at KE, the site closest to the increasing ice. This east-west difference is consistent with Letreguilly et al. [1991], who showed that temperature changes caused much more thinning in the west than in the east because the east Greenland ice sheet lies on higher elevation bedrock.

[11] The accuracy of these PGR predictions is not well understood. There could be local errors in either the ice model or the viscosity profile. Greenland deglaciation history is especially hard to reproduce, since much of the relevant geological information is still buried under ice, although there is a general pattern of retreat of the western margin of the inland ice during the last 80-150 years [Weidick et al., 1992] and many western outlet glaciers have retreated long distances (e.g., the calving front of JI has retreated $\sim 40 \mathrm{~km}$ since 1850 [Sohn et al., 1998]). There is no comparable evidence of retreat along the southeast margin, and the calving fronts of $\mathrm{HG}$ and $\mathrm{KG}$ changed by only a few $\mathrm{km}$ between 1933 and 2004 [Stearns and Hamilton, 2007], when they began to retrea rapidly. This evidence is not conclusive, but it gives no reason to suspect there might be significant post-2000 viscoelastic rebound caused by twentieth century ice variability.

\section{Volume Change Analysis}

\subsection{DEM Extraction Method and Error}

[12] Rates of volume change for the two nearest large outlet glaciers (Figure 1a) are quantified using sequential digital elevation models (DEMs). We generate DEMs of KG and $\mathrm{HG}$ using stereo satellite imagery collected by the ASTER (Advanced Spaceborne Thermal Emission and Reflection Radiometer) sensor. The procedure for DEM extraction was developed by Fujisada et al. [2005] and applied to KG and HG by Stearns and Hamilton [2007]. Multiple DEMs for each glacier were extracted from ASTER images acquired between July 2001 and July 2006. We difference the co-registered overlapping DEMs to compute volume changes with time [Stearns and Hamilton, 2007].

[13] The DEM uncertainties are a combination of random errors, such as satellite positioning error, image acquisition geometry and atmospheric conditions, and systematic biases. Stearns and Hamilton [2007] show that systematic errors are not significant for the images used in this study, and that the sequential DEMs have a high degree of repeatability as shown by an rms uncertainty of $10 \mathrm{~m}$ in individual elevations. This estimate is similar to values reported by Fujisada et al. [2005].

\subsection{DEM Results}

[14] Volume changes on the coastal portions (within $\sim 50 \mathrm{~km}$ of the calving fronts) of $\mathrm{KG}$ and $\mathrm{HG}$ were computed from the sequential ASTER-derived DEMs. Between July 21, 2001 and July 8, 2006, KG lost $119 \pm$ $17 \mathrm{~km}^{3}$ over a $1750 \mathrm{~km}^{2}$ area mapped with stereo images (Figure 1c) [Stearns and Hamilton, 2007]. HG lost roughly $59 \pm 9 \mathrm{~km}^{3}$ of ice over a $1040 \mathrm{~km}^{2}$ area between June 6,2002 and August 29, 2005 (Figure 1d).

[15] In both cases, these volume losses are minimum estimates. Mass loss is detected at the boundaries of our DEM coverage which implies larger areas of volume loss than are mapped in Figure 1c and 1d. As a means of estimating catchment-wide volume losses, we fit fourthorder polynomials to the observed elevation changes and extrapolate to the ice divides. Details of the polynomial extrapolations are provided by Stearns and Hamilton 
Table 1. Measured and Predicted Uplift ${ }^{\mathrm{a}}$

\begin{tabular}{lccccc}
\hline Baseline & $\begin{array}{c}\text { Uplift A, } \\
\text { GPS, mm }\end{array}$ & $\begin{array}{c}\text { Uplift B, } \\
\text { ICE-5G, mm }\end{array}$ & $\begin{array}{c}\text { Response C, } \\
\text { Elastic Effect, mm }\end{array}$ & $\begin{array}{c}\text { Response D, } \\
\text { HGL + KGL, mm }\end{array}$ & $\begin{array}{c}\text { Uplift E, } \\
\text { Residual, mm }\end{array}$ \\
\hline KU-KE & $29.4 \pm 2.1$ & 7.6 & 21.8 & 18.3 & $3.5 \pm 2.1$ \\
KU-TH & $29.3 \pm 3.0$ & -7.6 & 36.9 & 20.7 & $16.2 \pm 3.0$ \\
KU-QA & $22.4 \pm 2.0$ & -12.8 & 35.2 & 19.9 & $15.3 \pm 2.0$ \\
KU-SC & $13.8 \pm 3.0$ & -17.6 & 31.4 & 17.4 & $14.0 \pm 3.0$ \\
\hline
\end{tabular}

${ }^{a}$ Uplift A is observed uplift between July, 2001 and July, 2006 at KU relative to, KE, TH, QA and SC, respectively. Uplift B is ICE5G predicted relative uplift at KU between 2001-2006. Response $\mathrm{C}$ is the elastic response $(\mathrm{C}=\mathrm{A}-\mathrm{B})$ obtained after removing the viscoelastic response from the observed uplift. Response $\mathrm{D}$ is predicted elastic response due to mass loss of KG and $\mathrm{HG}$. Uplift $\mathrm{E}$ is residual uplift. $\mathrm{E}=\mathrm{A}-\mathrm{B}-\mathrm{D}$.

[2007]. The catchment basin of KG lost an estimated $310 \pm$ $77 \mathrm{~km}^{3}$ between July 21, 2001 and July 8, 2006, while the catchment basin of HG lost $180 \pm 60 \mathrm{~km}^{3}$ between June 6, 2002 and August 29, 2005 according to this analysis.

\section{GPS Results and PGR Correction}

[16] The smoothed GPS results at KU relative to KE (solid line in Figure 2d) show a total uplift of the crust of $29.4 \pm 2.1 \mathrm{~mm}$ between July 2001 and July 2006. Table 1, uplift A shows uplift at KU relative to KE, TH, QA and SC. Column B shows ICE-5G predicted PGR uplift at KU between July 2001 and July 2006 relative to the other GPS sites. Since ICE-5G predicts a present-day uplift rate of $-1.7 \mathrm{~mm} \mathrm{yr}^{-1}$ at $\mathrm{KU}$ and $-3.3 \mathrm{~mm} \mathrm{yr}^{-1}$ at $\mathrm{KE}, \mathrm{KU}$ experiences a PGR uplift rate relative to KE of $1.6 \mathrm{~mm} \mathrm{yr}^{-1}$. Between July 2001 and July 2006 KU-KE will thus experience a total uplift of $7.6 \mathrm{~mm}$. Column $\mathrm{C}(=\mathrm{A}-\mathrm{B})$ lists the measured uplift at KU after removing the PGR effects, and shows total relative uplift at KU of between 22 and $37 \mathrm{~mm}$. This uplift is presumably due to the earth's elastic response to ongoing changes in ice.

\section{Earth's Elastic Response to Ongoing Changes in Ice}

\subsection{Mass Losses From Helheim and Kangerdlugssuaq Glaciers}

[17] The KU GPS receiver is only $\sim 90 \mathrm{~km}$ from the HG front. Thus, a portion of the observed uplift at KU may be due to the earth's elastic response to ongoing mass loss of this glacier. To estimate the amplitude of the uplift, we convert the calculated volume losses to mass assuming a density equal to that of ice $\left(910 \mathrm{~kg} \mathrm{~m}^{-3}\right)$, and convolve with Farrell's [1972] elastic Green's function for vertical displacements. We ignore viscous effects because the earth's viscous decay times are orders of magnitude longer than the time scale of the ice loss; though we cannot categorically rule out the possibility of much shorter decay times caused by local transient rheological effects [Ivins and Sammis, 1996]. We use a fine-scale $150 \times 150 \mathrm{~m}$ grid to represent the distribution of mass loss in the coastal regions. The catchment-wide volume losses are gridded to a coarser resolution of $5 \times 5 \mathrm{~km}$.

[18] The total predicted uplift at KU due to the HG mass loss between June 6, 2002 and August 29, 2005 is $16.6 \pm$ $5.5 \mathrm{~mm}$, using the catchment-wide volume loss estimate. Repeating this analysis for $\mathrm{KG}$, we conclude that the $\mathrm{KG}$ catchment caused a total KU uplift of $5.4 \pm 1.3 \mathrm{~mm}$ between July 21, 2001 and July 8, 2006. KG caused less uplift than
$\mathrm{HG}$, because $\mathrm{KU}$ is much further from $\mathrm{KG}(\sim 370 \mathrm{~km})$. Together, mass loss across the catchments of these two glaciers causes a total uplift of $22.0 \pm 5.7 \mathrm{~mm}$ at $\mathrm{KU}$ (see Table 2).

[19] The mass loss of KG and HG is huge and thus causes significant uplift even at the more distant sites: $4.6 \mathrm{~mm}$ at $\mathrm{SC}, 3.7 \mathrm{~mm}$ at KE, $2.1 \mathrm{~mm}$ at QA and $1.3 \mathrm{~mm}$ at TH. Table 1 , response D shows the earth's elastic response at KU relative to these sites.

[20] The DEM time spans for HG and KG are not the same. The HG time span is about one year shorter on each end than the KU GPS time span. However, we assume no significant volume loss on the HG between July 21, 2001 and June 6, 2002 and between August 29, 2005 and June 8, 2006. The assumption of no volume loss between August, 2005 and June, 2006 is supported by Stearns and Hamilton [2007] who observed no surface elevation change on the across-flow elevation profile and the along-flow elevation profile near the HG front. Moreover, since the smoothed GPS results at KU relative to KE (solid line in Figure 2d) do not show notable uplift between July 21, 2001 and June 6, 2002, we assume no volume loss during this period. However, the smoothed uplift seems to continue unabated during 2004-2007. This is consistent with figure 3 of Velicogna and Wahr [2006], which shows steady mass loss in south Greenland between spring 2004 and spring 2006. Thus, we assume the residual uplift in column $\mathrm{E}$ is caused by melting from elsewhere along the southeast coast (Figure 1b).

\subsection{Mass Loss Along the Southeast Coast}

[21] The Table 1, uplift E values for the residual uplift at KU relative to TH, QA and SC, are consistent with one another. Temporarily ignoring the KU-KE results, we propose that the residual uplift of $15 \mathrm{~mm}$ between $\mathrm{KU}$ and the other 3 sites could be caused by thinning along the ice sheet margin in southeast Greenland outside of HG \& KG. Repeat laser altimetry shows mass loss throughout this region, with

Table 2. Elastic Uplift at KU, and Ice Loss Characteristics, Due to the Assumed Coastal Mass Loss Between July 2001 and July 2006, the Mass Loss of KG Between July 2001 and July 2006, and the Mass Loss of HG Between June 2002 and August 2005

\begin{tabular}{lccc}
\hline & Uplift, $\mathrm{mm}$ & Volume Loss, $\mathrm{km}^{3}$ & Area, $\mathrm{km}^{2}$ \\
\hline Helheim Gl. & 16.6 & 180 & 48319 \\
Kangerdlugssuaq Gl. & 5.4 & 310 & 51089 \\
Coastal thinning & 16.0 & 271 & 60600 \\
Total & 38.0 & 761 & 160008 \\
\hline
\end{tabular}


most of that loss occurring at elevations below $2500 \mathrm{~m}$ [Krabill et al., 2004]. The assumption of mass loss in southeast Greenland is further supported by the results of Rignot and Kanagaratnam [2006], who detected a huge mass loss in this region using satellite radar interferometry (table 1 area 13 of Rignot and Kanagaratnam [2006]).

[22] To model the possible crustal uplift caused by this mass loss, we assume that ice sheet thinning occurred between $62^{\circ} \mathrm{N}$ and $66^{\circ} \mathrm{N}$, and between sea level and $2500 \mathrm{~m}$ elevation. This region roughly corresponds to area 13 of Rignot and Kanagaratnam [2006]. We assume the total thinning between July, 2001 and July, 2006 (the GPS time span) was a maximum of $16 \mathrm{~m}$ at sea level, and decreased linearly with increasing elevation, to vanish at $2500 \mathrm{~m}$ elevation. This gives a total 5-year ice volume loss of about $271 \mathrm{~km}^{3}$, which is similar to Rignot and Kanagaratnam's [2006] estimate for their area 13. Using this simple ice model to load the earth yields total uplift values of $16.0 \mathrm{~mm}$ at KU (Table 2), and of $3.0 \mathrm{~mm}, 4.5 \mathrm{~mm}, 1.1 \mathrm{~mm}$, and $0.1 \mathrm{~mm}$ at $\mathrm{KE}, \mathrm{QA}, \mathrm{SC}$, and $\mathrm{TH}$, respectively. Thus, the predicted effects on the uplift of KU relative to QA, SC, and $\mathrm{TH}$ are on the order of $11.5-15.5 \mathrm{~mm}$, which is in reasonable agreement with the Table 1, uplift $\mathrm{E}$ values for those sites.

[23] The residual uplift of KU relative to KE is much smaller $(3.5 \pm 2.1 \mathrm{~mm})$ than the residual uplift relative to the other three sites. It is unlikely that this reflects KE uplift caused by ongoing mass losses adjacent to KE. Observations from satellite radar interferometry near KE (Table 1 area 19 of Rignot and Kanagaratnam [2006]) do not indicate significant ice mass change.

[24] The closet outlet glacier to KE is JI (250 km distant), which is a major contributor to the mass balance of the inland ice sheet. To estimate the amplitude of the elastic motion due to thinning of JI, we assume the JI catchment lost ice at a rate of $16 \mathrm{~km}^{3} / \mathrm{yr}$ during 2001-2006, a rate chosen to coincide with Rignot and Kanagaratnam's [2006] estimate of 2005 ice loss in their area 20, and giving a total 5 -year ice volume loss of $80 \mathrm{~km}^{3}$. Assuming, for simplicity, that all this ice loss occurred near the JI grounding line, we obtain a total $\mathrm{KE}$ uplift of $3 \mathrm{~mm}$ over a 5 -year period. Thus, the removal of the elastic response at $\mathrm{KE}$ due to thinning along the southeast coast ( $3 \mathrm{~mm}$ of uplift) and the thinning of JI ( $3 \mathrm{~mm}$ of uplift), reduces the residual uplift of KU relative to KE by $6 \mathrm{~mm}$. If we also remove the $16 \mathrm{~mm}$ of uplift at KU caused by the proposed southeast thinning, we obtain an unexplained KU-KE residual uplift of $-6.5 \pm$ $2.1 \mathrm{~mm}$.

[25] This residual KU-KE uplift could indicate that ICE$5 \mathrm{G}$ overestimates the PGR subsidence rate at KE. The Greenland component of the global ICE-5G model predicts present-day subsidence rates that are as large as $7 \mathrm{~mm} \mathrm{yr}^{-1}$ at some southwest Greenland locations [Tarasov and Peltier, 2002, Figure 14a]. This subsidence is due to recent regrowth of ice mass to the mid-Holocene climatic optimum. One possible explanation for the anomalous uplift for KU-KE is that ICE-5G predicts too much ice regrowth, causing present-day land subsidence at KE to be overestimated by $\sim 1 \mathrm{~mm} / \mathrm{yr}$.

[26] If the KE ICE-5G rate is correct, we could still explain the anomalous KU-KE uplift by assuming either that (1) the 2001-2006 JI volume loss was 2-3 times larger than assumed above; or (2) there was negligible thinning of
$\mathrm{JI}$ and in southeast Greenland (though with $\mathrm{HG}$ and $\mathrm{KG}$ still thinning as described above), but that ICE-5G predicts too much uplift at TH, QA and SC by $\sim 3 \mathrm{~mm} \mathrm{yr}^{-1}$ at each site. Explanation (2) seems unlikely, since it is inconsistent with Rignot and Kanagaratnam's [2006] observations of large mass losses in those regions.

\section{Conclusions}

[27] The GPS measurements at KU relative to TH, QA and SC indicate a total crustal uplift of $\sim 35 \pm 5 \mathrm{~mm}$ between July 2001 and July 2006, after PGR effects have been removed. Most of the observed uplift is due to the earth's elastic response to rapid mass loss caused by dynamic thinning on large outlet glaciers. HG lost roughly $180 \mathrm{~km}^{3}$ of ice between June 2002 and August 2005, which we estimate caused an uplift of $16.6 \mathrm{~mm}$ at KU. The amplitude of the elastic motion at KU due to an ice loss of $310 \mathrm{~km}^{3}$ of KG between July 2001 and July 2006 is $5.4 \mathrm{~mm}$

[28] When we subtract the effects of these glaciers from all GPS uplift rates, we are left with $\sim 15 \mathrm{~mm}$ of unexplained uplift of KU relative to TH, QA, and SC. This remaining uplift is probably due to mass loss from thinning elsewhere along the southeastern ice sheet margin. A simple model of this mass loss predicts $16.0 \mathrm{~mm}$ of absolute uplift at $\mathrm{KU}$, and $12.5-15.5 \mathrm{~mm}$ of relative uplift between $\mathrm{KU}$ and TH, QA, and SC. Adding the ice loss values from this model to the dynamic thinning estimates of $\mathrm{HG}$ and $\mathrm{KG}$, suggests a total ice volume loss over $\sim 5$ years of $761 \mathrm{~km}^{3}$ (or $160 \mathrm{~km}^{3} \mathrm{yr}^{-1}$ ).

[29] The measured uplift of KU relative to KE is inconsistent with its uplift relative to TH, QA and SC. About half that inconsistency can be explained by including elastic uplift at KE caused by thinning of JI and by ice in southeast Greenland outside of HG and KG. The remaining half of the inconsistency is likely due to some combination of errors in the ICE-5G predictions of PGR and errors in our assumptions about ongoing thinning. It could, for example, be explained if the ICE-5G deglaciation model over-estimates the PGR subsidence rate at KE by $\sim 1 \mathrm{~mm} / \mathrm{yr}$, or if the thinning of JI is much larger than that predicted from radar interferometric observations.

[30] GPS observations at KU suggest significant acceleration of ice mass loss in spring 2004. This acceleration coincided with observed rapid increases in flow speed of $\mathrm{HG}$ and KG. Accelerating ice mass loss in spring 2004 is supported by satellite gravity surveys by GRACE [Velicogna and Wahr, 2006]. This increased loss of mass from southeast Greenland is probably a significant fraction of the ice sheet's sea level contribution, and is causing a rapid elastic adjustment of the earth's crust, as the results show.

[31] Acknowledgments. We thank two anonymous reviewers for their comments. J. Wahr's effort was partially supported by NASA grants NNG04GF02G and NNX06AH37G to the University of Colorado. L. A. Stearns and G. S. Hamilton were supported by NASA's cryospheric sciences program. S. A. Khan's effort was partially supported by KVUG.

\section{References}

Altamimi, Z., X. Collilieux, J. Legrand, B. Garayt, and C. Boucher (2007), ITRF2005: A new release of the International Terrestrial Reference Frame based on time series of station positions and Earth Orientation Parameters, J. Geophys. Res., 112, B09401, doi:10.1029/2007JB004949. 
Dietrich, R., H.-G. Maas, M. Baessler, A. Rulke, A. Richter, E. Schwalbe, and P. Westfeld (2007), Jakobshavn Isbr, West Greenland: Flow velocities and tidal interaction of the front area from 2004 field observations, J. Geophys. Res., 112, F03S21, doi:10.1029/2006JF000601.

Farrell, W. (1972), Deformation of the Earth by surface loads, Rev. Geophys., 10, 761-797.

Fujisada, H., G. B. Bailey, G. G. Kelly, S. Hara, and M. J. Abrams (2005), ASTER DEM performance, IEEE Trans. Geosci. Remote Sens., 43, 2707-2714.

Howat, I. M., I. Joughin, S. Tulaczyk, and S. Gogineni (2005), Rapid retreat and acceleration of Helheim Glacier, east Greenland, Geophys. Res. Lett., 32, L22502, doi:10.1029/2005GL024737.

Ivins, E. R., and C. G. Sammis (1996), Transient creep of a composite lower crust: 1. Constitutive theory, J. Geophys. Res., 101, 27,981-28,004.

Joughin, I., W. Abdalati, and M. Fahnestock (2004), Large fluctuations in speed on Greenland's Jakobshavn Isbrae glacier, Nature, 432, 608-610, doi:10.1038/nature03130.

Krabill, W., et al. (2004), Greenland Ice Sheet: Increased coastal thinning, Geophys. Res. Lett., 31, L24402, doi:10.1029/2004GL021533.

Letreguilly, A., N. Reeh, and P. Huybrechts (1991), The Greenland ice sheet through the last glacial-interglacial cycle, Palaeogeogr. Palaeoclimat. Palaeoecol., 90, 385-394.

Peltier, W. R. (2004), Global glacial isostasy and the surface of the ice-age Earth: the ICE-5G (VM2) model and GRACE, Annu. Rev. Earth Planet. Sci., 32, 111-149.

Press, W. H., W. T. Vetterling, S. A. Teukolsky, and B. P. Flannery (1992), Numerical Recipes in Fortran 77, 2nd ed., pp. 494-502, Cambridge Univ. Press, Cambridge, U. K.

Rignot, E., and P. Kanagaratnam (2006), Changes in the velocity structure of the Greenland ice sheet, Science, 311, 986-990, doi:10.1126/ science. 1121381 .

Sohn, H. G., K. C. Jezek, and C. J. van der Veen (1998), Jakobshavn Glacier, West Greenland: 30 years of spaceborne observations, Geophys. Res. Lett., 25, 2699-2702.
Stearns, L. A., and G. S. Hamilton (2007), Rapid volume loss from East Greenland outlet glaciers quantified using repeat stereo satellite imagery, Geophys. Res. Lett., 34, L05503, doi:10.1029/2006GL028982.

Tarasov, L., and W. R. Peltier (2002), Greenland glacial history and local geodynamic consequences, Geophys. J. Int., 150, 198-229.

Velicogna, I., and J. Wahr (2006), Acceleration of Greenland ice mass loss in spring 2004, Nature, 433(21), 329-331, doi:10.1038/nature05168.

Wahr, J., T. van Dam, K. Larson, and O. Francis (2001), Geodetic measurements in Greenland and their implications, J. Geophys. Res., 106, $16,567-16,582$.

Weidick, A., C. E. Bøggild, and N. T. Knudsen (1992), Glacier inventory and atlas of West Greenland. Rapp. Groenl. Geol. Unders., 158, 194 pp. Zumberge, J. F., M. B. Heflin, D. C. Jefferson, M. M. Watkins, and F. H. Webb (1997), Precise point positioning for the efficient and robust analysis of GPS data from large networks, J. Geophys. Res., 102, 50055017.

O. Francis and T. van Dam, Faculty of Sciences, Technology, and Communication, 162 A, avenue de la Faïencerie, University of Luxembourg, L-1511, Luxembourg.

G. S. Hamilton and L. A. Stearns, Climate Change Institute, University of Maine, Orono, ME 04469, USA.

S. A. Khan, Danish National Space Center, Technical University of Denmark, DK-2100 Copenhagen, Denmark. (abbas@space.dtu.dk)

K. M. Larson, Department of Aerospace Engineering Sciences, University of Colorado, Boulder, CO 80309, USA.

J. Wahr, Department of Physics and Cooperative Institute for Research in Environmental Sciences, University of Colorado, Boulder, CO 80309 , USA. 